Delft University of Technology

\title{
Assessment of an Increased-Fidelity Aeroelastic Experiment for Free Flying Wing Response to Gust Excitation
}

Sodja, J.; De Breuker, R.

DOI

10.2514/6.2022-2418

Publication date

2022

Document Version

Final published version

Published in

AIAA SCITECH 2022 Forum

\section{Citation (APA)}

Sodja, J., \& De Breuker, R. (2022). Assessment of an Increased-Fidelity Aeroelastic Experiment for Free Flying Wing Response to Gust Excitation. In AIAA SCITECH 2022 Forum [AIAA 2022-2418] (AIAA Science and Technology Forum and Exposition, AIAA SciTech Forum 2022). https://doi.org/10.2514/6.2022-2418

\section{Important note}

To cite this publication, please use the final published version (if applicable).

Please check the document version above.

\section{Copyright}

Other than for strictly personal use, it is not permitted to download, forward or distribute the text or part of it, without the consent of the author(s) and/or copyright holder(s), unless the work is under an open content license such as Creative Commons.

\section{Takedown policy}

Please contact us and provide details if you believe this document breaches copyrights.

We will remove access to the work immediately and investigate your claim. 


\title{
Assessment of an Increased-Fidelity Aeroelastic Experiment for Free Flying Wing Response to Gust Excitation
}

\author{
Jurij Sodja* and Roeland De Breuker ${ }^{\dagger}$ \\ Delft University of Technology, The Netherlands
}

\begin{abstract}
The paper proposes a methodology for increased-fidelity aeroelastic testing in a wind tunnel environment to improve the correlation between the aeroelastic response measured in a wind tunnel experiment and the aeroelastic response observed on an aircraft in flight. The focus of the current study is to assess the potential of the proposed methodology to improve load and response predictions by emulating the motion of a free flying aircraft at the root of the wing. For this purpose a numerical aeroelastic model of a free flying aircraft is used to obtain a reference aeroelastic response to gust excitation. The model is reduced to obtain an aeroelastic model comprising only the main wing of the aircraft which is clamped at the root as if it would be mounted in a wind tunnel. The wing is then subjected to five different motion profiles emulating the free flight to a various degree. The considered motion profiles are clamped boundary condition, heave-pitch motion of a free flying aircraft, motion profile following the angle of attack of the aircraft, and two modified heave-pitch motion profiles which match the angle of attack and the aerodynamic loads in the wind tunnel with those in free flight. The study shows that the considered motion profiles can significantly improve the correlation between the wind tunnel experiment and free flight. However, the effectiveness of each motion profile strongly depends on the gust length which indicates that the optimum motion profile depends on the gust length. Finally, the paper presents a conceptual design of a wind tunnel demonstrator to serve as a proof-of-concept for the proposed methodology.
\end{abstract}

\section{Introduction}

TCREASED accuracy numerical models and increasing computational resources allow us to ever better predict the aeroelastic behaviour of modern aircraft numerically. Nevertheless, the need for experimental validation of such predictions by means of extensive and costly wind tunnel and flight tests remains essential.

Wind tunnel experiments dealing with gust and turbulence response or stability margins of aeroelastic structures can be performed in many different ways as far as mounting and boundary conditions of the aeroelastic model are concerned. The boundary condition used in the experiment also depends on the size and complexity of the tested aeroelastic model. Most prolific experiments of this kind comprise a flexible semi-wing clamped to a fixed support ${ }^{1-6}$ or support which moves according to a prescribed motion trajectory. ${ }^{7,8}$ Clamped boundary condition is also often employed with semi-aircraft aeroelastic models such as in the case of NASA ST4 model. ${ }^{9,10}$

The clamped boundary condition does not mimic the boundary condition of a wing mounted on a freeflying aircraft. Various mechanisms were proposed in the past to better emulate the boundary conditions of a free-flying aircraft in the wind tunnel tests. Tang et al., ${ }^{11}$ Jordan and Smith $^{12}$ and Gaukroger et al., ${ }^{13}$ amongst others, suspended a flexible wing using elastic springs to emulate the mass and inertia properties of the rest of the aircraft. Such mechanisms effectively relax the clamped boundary condition, however, if the aircraft configuration is changed the mechanism has to be manually reconfigured, for instance the

*Senior researcher, Faculty of Aerospace Engineering, Aerospace Structures and Computational Mechanics, Kluyverweg 1, 2629 HS Delft; J.Sodja@tudelft.nl

${ }^{\dagger}$ Associate Professor, Faculty of Aerospace Engineering, Aerospace Structures and Computational Mechanics, Kluyverweg 1, 2629 HS Delft; R.DeBreuker@tudelft.nl 
supporting springs have to be physically exchanged. Even though Jordan and Smith ${ }^{12}$ clearly showed the effect of boundary condition stiffness on the flutter properties of the tested wing, there is no elaboration on how representative is such boundary condition of that of a free-flying aircraft.

To minimise the interference of the mounting conditions on the aeroelastic response, scaled aeroelastic models of full aircraft suspended by a system of cables have been tested as well. NASA, amongst others, has a long history of performing such tests starting with the first flutter tests of Lockheed Electra in $1960^{\mathrm{a}}$. More recently, an aeroelastic wind tunnel experiment of a scaled X-DIA aircraft was developed by Ricci et al. ${ }^{14}$ to investigate active flutter suppression. The disadvantage of such tests is their complexity, high count of required hardware and scaling, since such models need to be substantially scaled down in size to fit in the wind tunnel. That makes it challenging to fulfil all the similarity laws required to obtain results which are representative of a full-scale aircraft.

As shown, each conventional approach to aeroelastic tests has limitations and drawbacks. Most notable are the clamped boundary condition in the case of semi-wing models and high complexity of the physical test model in the case of semi- and full-aircraft model. Recently, there were attempts to develop actuated support systems for rigid and elastic semi-wing and semi-aircraft models to mitigate some of these issues. Fonte et al. ${ }^{15}$ developed a weight augmentation system to simulate weight of a semi-aircraft model vertically attached to a sliding platform. An actuator was used to exert a constant force equal to the weight of the model. Ertveldt et al. ${ }^{16}$ developed an active aeroelastic test bench to study unsteady aerodynamic effects. In this case a rigid airfoil was subjected to forced motion provided by a pair of linear actuators. The platform could, in principle, also be actuated in closed-loop configuration to mimic linear or non-linear stiffness behaviour. Finally, Tang et al. ${ }^{17}$ developed a virtual stiffness-damping system to control the motion of a typical section airfoil. Instead of springs and dampers, actuators controlled in closed-loop configuration were used to provide stiffness and damping to the aeroelastic system. The system was used to simulate limit cycle oscillations (LCOs).

The current paper evaluates the potential of the increased-fidelity aeroelastic tests by comparing an aeroelastic gust response of an aircraft in free flight to an aeroelastic response of the wing obtained in a simulated wind tunnel experiment with various mounting boundary conditions. The wind tunnel experiment is simulated by reducing the full aircraft model to an aeroelastic model of the main wing clamped at the root and mounted on an actuated platform. The wing root is then subjected to a prescribed motion in the heave and pitch degree of freedom (DOF). The motion is obtained from a numerical model of a free flying aircraft.

The paper is organised as follows. First, the methodology for increased-fidelity aeroelastic testing is introduced in Sec. II. Next, the selected aircraft model ${ }^{18}$ and its implementation in the open-source aeroelastic analysis framework called SHARPy ${ }^{19}$ are described in Sec. III. Motion profiles considered for emulating the free flight are explained in Sec. IV. Section V discusses the obtained numerical results and Sec. VI presents the conceptual design of the wind tunnel demonstrator to be used to validate the proposed methodology. Finally, all the pertinent conclusions are collected in Sec. VII.

\section{Increased-Fidelity Aeroelastic Testing}

The increased-fidelity aeroelastic testing aims to improve the aeroelastic experiments conducted in a wind tunnel environment in three ways. First, the correlation between the aeroelastic response of a test subject in the wind tunnel and in free flight is improved by providing a more realistic mounting conditions and mounting response in the wind tunnel. Second, the hardware complexity of the wind tunnel model is reduced, since only a specific subcomponent of an aircraft, such as the main wing, is required in a physical form. Finally, the proposed methodology simplifies the execution of parametric wind tunnel tests, since many parameters pertinent to the aircraft configuration can be modified in the digital twin of the model without changing the hardware in the wind tunnel.

The proposed methodology extends the work of Ertveldt et al. ${ }^{16}$ and Tang et al ${ }^{17}$ by including a digital twin of the aircraft in the control loop that governs the motion of the actuated support system to which a wind tunnel model is attached as shown in 1. The aim of the proposed digital twin methodology is to use software-in-the-loop to increase the fidelity of the wind tunnel test with respect to the "fixed" and "forced-motion" clamped boundary conditions while not altering the complexity of the tests. In addition, the methodology for increased-fidelity aeroelastic testing enables one to perform parametric and explorative

\footnotetext{
${ }^{\mathrm{a}}$ source: https://history.nasa.gov/SP-440/ch6-5.htm, accessed October 30, 2019
} 
aeroelastic experiments in an efficient way by varying the parameters of the aircraft model, such as payload mass, centre of gravity location, fuselage dimensions, and empennage size.

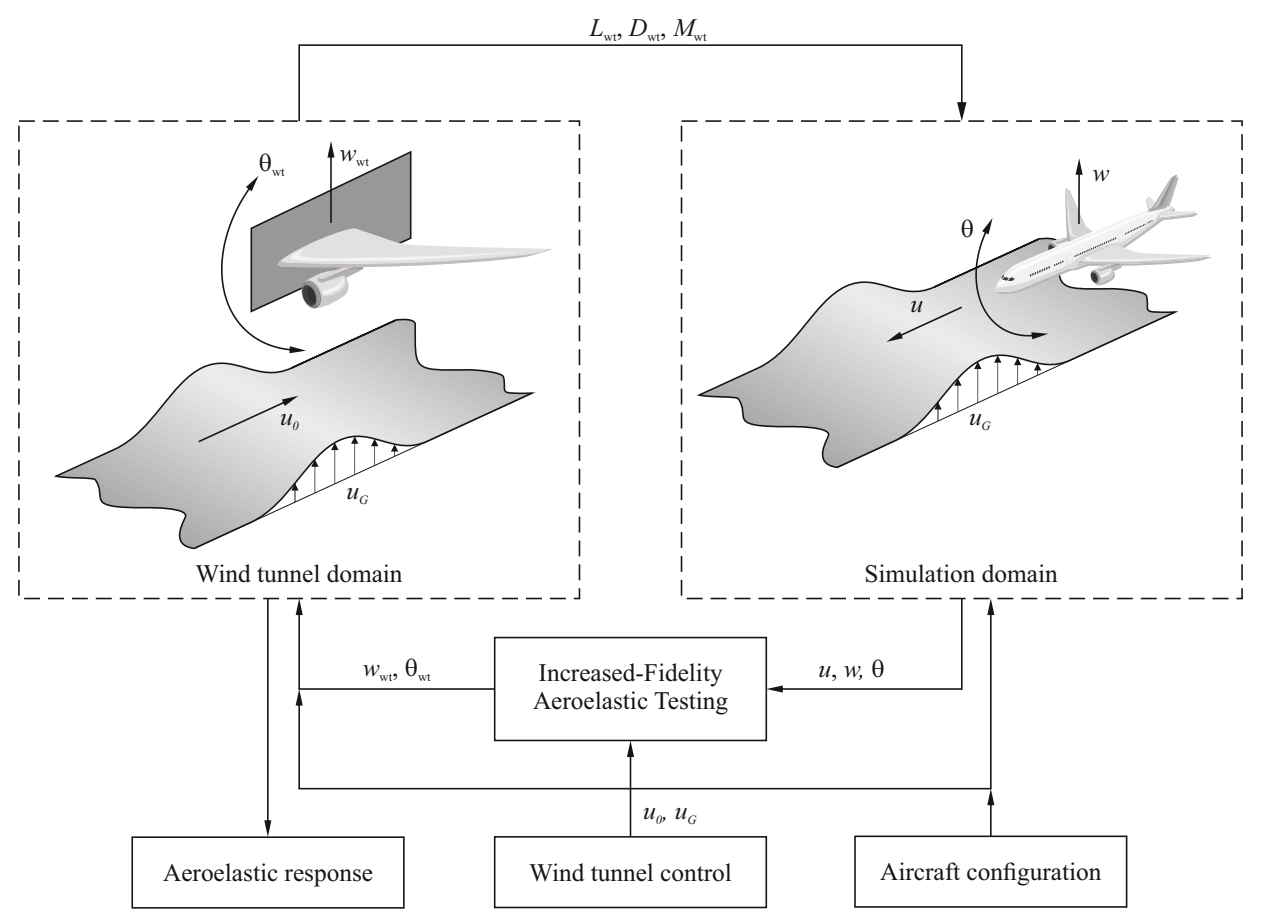

Figure 1. Increased-fidelity aeroelastic testing

As shown in Fig. 1, the proposed methodology envisions a feedback loop between the wind tunnel domain and the simulations domain, where the loads measured on the wing in a wind tunnel are fed into the simulation domain to predict the flight dynamic response of the aircraft which is then processed by the Increased-fidelity aeroelastic testing block to derive the wind tunnel motion. The assumption is that the loads measured on the wing will allow for a quick and accurate prediction of the aircraft free flight response since it is no longer necessary to estimate these loads numerically. This might be especially beneficial if non-linear phenomena, such as flow separation or shock motion, are expected to occur. On the other hand, the proposed methodology can be simplified, by simulating the free-flight response of the aircraft in advance and then actuate the wind tunnel model using a prescribed motion profile in a feedforward manner.

Finally, the idea of increased-fidelity aeroelastic testing can also be inverted. Instead of simulating specific mounting conditions of the test model in the wind tunnel, the approach can be used to simulate a specific behaviour of a subcomponent of the physical model. For example, the amount of free-play in the control surfaces, or the stiffness of the engine pylon.

\section{Aircraft Model}

A numerical model of a High-Altitude Long-Endurance (HALE) aircraft devised by Carre and Palacios ${ }^{18}$ is used as a numerical model to study the effect of various boundary conditions that could be used in wind tunnel experiments on the aeroelastic response of the tested wing. The HALE aircraft along with its basic dimensions is shown in Fig. 2 while the structural stiffness and mass properties are summarised in Table 1. The HALE aircraft is setup in such a way that the fuselage and empennage are stiff and lightweight in comparison to the main wing. In addition, a mass point of $50 \mathrm{~kg}$ is added at the centre of the wing to represent the non-structural mass of the aircraft. In such configuration, it is expected that the main aeroelastic effects originate from the deformation of the wing, while the fuselage and empennage ensure a corresponding flight dynamic response.

The HALE model is implemented in an open-source aeroelastic analysis framework called SHARPy which is developed by Palacios et al. ${ }^{19}$ The framework allows for a time-resolved dynamic aeroelastic simulation of either a free flying aircraft or an aircraft subjected to a prescribed time-dependent motion profile and 


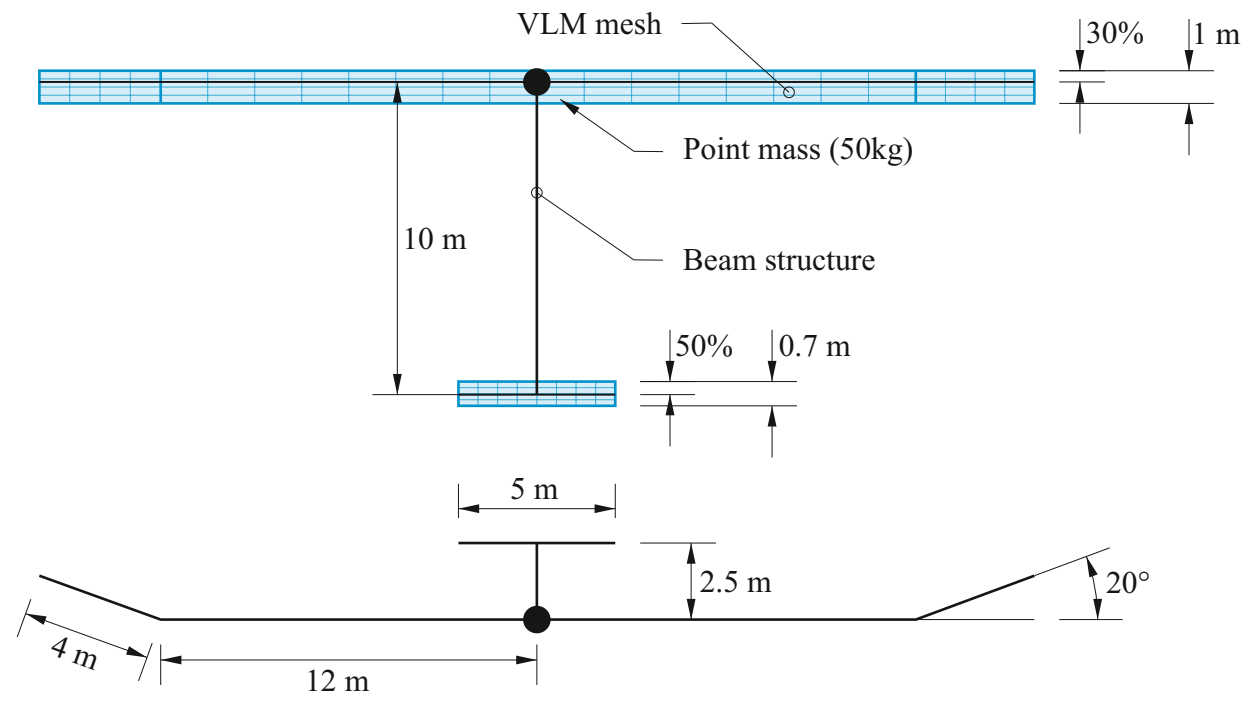

Figure 2. HALE aircraft (adopted from Carre and Palacios ${ }^{18}$ )

Table 1. Physical properties of the HALE aircraft (adopted from Carre and Palacios ${ }^{18}$ )

\begin{tabular}{rrr}
\hline \multicolumn{1}{c}{ Parameter } & Unit & Quantity $^{\dagger}$ \\
\hline specific mass $m$ & {$[\mathrm{~kg} / \mathrm{m}]$} & $0.75,0.1,0.1$ \\
specific moment of inertia $J$ & {$\left[\mathrm{kgm}^{2} / \mathrm{m}\right]$} & $0.1,0.01,0.01$ \\
tensile stiffness, $E A$ & {$[\mathrm{~N}]$} & $1.5 \cdot 10^{6}, 1.5 \cdot 10^{7}, 1.5 \cdot 10^{7}$ \\
shear stiffness, $G A$ & {$[\mathrm{~N}]$} & $1.5 \cdot 10^{6}, 1.5 \cdot 10^{7}, 1.5 \cdot 10^{7}$ \\
out-of-plane bending stiffness, $E I_{y}$ & {$\left[\mathrm{Nm}^{2}\right]$} & $3 \cdot 10^{4}, 3 \cdot 10^{5}, 3 \cdot 10^{5}$ \\
in-plane bending stiffness, $E I_{z}$ & {$\left[\mathrm{Nm}^{2}\right]$} & $6 \cdot 10^{6}, 6 \cdot 10^{7}, 6 \cdot 10^{7}$ \\
torsional stiffness, $G J$ & {$\left[\mathrm{Nm}^{2} / \mathrm{rad}\right]$} & $1.5 \cdot 10^{4}, 1.5 \cdot 10^{5}, 1.5 \cdot 10^{5}$ \\
\hline
\end{tabular}

$\dagger$ values corresponding in order to wing, fuselage, and tail 
external forces. Moreover, the framework includes various gust models such as 1-cosine or general timevarying gust model. Consequently, SHARPy is well suited for, first, obtaining an aeroelastic response of a free flying aircraft, and, second, applying this response as a prescribed motion profile in the simulation of an aeroelastic experiment in the wind tunnel.

To assess the potential of the proposed methodology for increased-fidelity aeroelastic testing, a number of simulations are performed with the HALE model. First, a free flight simulation of the HALE aircraft in trimmed condition at a flight velocity of $u_{0}=10 \mathrm{~m} / \mathrm{s}$ is performed over a range of gust lengths to obtain the reference aeroelastic response of the main wing in free flight. A span-wise uniform, vertical 1-cosine gust profile is used with the gust lengths in the range from $l_{G}=5 \mathrm{~m}$ up to $l_{G}=60 \mathrm{~m}$ and gust intensity equal to $w_{G 0}=0.2 u_{0}$. The gust profile is give as:

$$
w_{G}(t)=\frac{w_{G 0}}{2}\left[1-\cos \left(\frac{2 \pi u_{0} t}{l_{G}}\right)\right]
$$

It is important to point out, that the current assessment treats the simulated free flight motion in a feedforward manner, which differs from the feedback approach proposed in Sec. II, where the loads on the wing are measured in the wind tunnel and introduced into the numerical model of the aircraft to determine the corresponding free flight motion and consequently, the motion used to actuate the wind tunnel model. However, in the current assessment, the same aeroelastic model of the wing is used for the full aircraft simulation and for the simulated wind tunnel experiment, hence it is expected that the predicted loads generated by the main wing are the same assuming that the interference effects from the other lifting surfaces on the aircraft, such as the empennage, are negligible. Consequently, one can assume that the motion of the wind tunnel model in a feedback manner would resemble closely the motion derived from the free flight motion in a feedforward manner. In this sense, the current assessment approach presents the best possible scenario. On the other hand, if one wanted to assess the effect of physical constraints on the imposed motion, or the effect of a time delay introduced by the feedback loop, then one would have to setup the assessment in a feedback configuration, whereby these effects can be introduced.

\section{Derivation of Motion Profiles}

The initial HALE model is reduced to an aeroelastic model comprising only the main wing which is clamped at the root to simulate a rigid attachment to the wind tunnel balance. The reduced HALE model is then used to simulate the effect of mimicking the free flight motion on the wing structural loads and deformations. First, a clamped mounting condition, enforcing no motion at the root of the wing, and a heave-pitch motion, obtained from the free flight simulations, are simulated to obtain an aeroelastic response equivalent to a conventional wind tunnel experiment and to observe the effect of heave and pitch motion on the aeroelastic response of the wing under wind tunnel conditions.

In the next step, the free flight motion is modified to improve the agreement between the free flight aeroelastic response and the aeroelastic response observed in the wind tunnel experiment. To do so, there are two important aspects to consider. First, the aircraft pitch angle, $\theta$, and the angle of attack, $\alpha$, do not coincide in general as shown in Fig. 3. These two angles are equal only in horizontal trimmed flight while they differ during a transient response to an external perturbation such as gust impingement. ${ }^{20}$ Second, it is important to realise that during a transient response the flight velocity of the aircraft changes in magnitude which affects the dynamic pressure, $q_{d}$, and thereby the aerodynamic forces exerted on the aircraft. Based on these insights, three modified motion profiles for the heave and pitch degree of freedom are derived from the free flight motion to improve the measured response in the wind tunnel.

The first modified motion profile is based on the fact that the aerodynamic forces depend primarily on the effective angle of attack of the aircraft which in turn results from the combination of aircraft's heave and pitch motion. To simplify the motion profile used in the wind tunnel, it is proposed to eliminate the heave motion and to substitute the pitch motion with the instantaneous angle of attack which can be expressed as:

$$
\alpha(t)=\arctan \left(\frac{w_{A}(t)}{u_{A}(t)}\right)
$$

where, according to Fig. $3, u_{A}$ and $w_{A}$ represent the instantaneous velocity component along $x_{A}$ and $z_{A}$ in the body-fixed frame of reference (FoR) $A$. This way, the wind tunnel experiment is simplified, since the 
wing only needs to be actuated around the pitch axis.

The second motion profile is based on the insight that the free stream velocity in the wind tunnel can not be varied very quickly and efficiently, since a wind tunnel usually takes too long (at an order of $10 \mathrm{~s}$ ) to react to the changes in commanded free-stream velocity. As a result, the free stream velocity, $u_{0}$, which correspond to the horizontal component of the flight velocity, $u_{G}$, in the global FoR $G$, can not change while emulating a transient response in the wind tunnel. To account for this difference, it is proposed to modify the pitch motion to recover the aircraft's angle of attack in free flight. First, a new angle $\gamma_{W T}$ is determined from the heave velocity in FoR $G, w_{G}$ and the free-stream velocity, $u_{0}$, as:

$$
\gamma_{W T}(t)=\arctan \left(\frac{w_{G}(t)}{u_{0}}\right)
$$

The new pitch angle, $\theta_{W T}$, is then calculated by summing $\alpha(\mathrm{t})$ from Eq. 2 and $\gamma_{W T}$ from Eq. 3:

$$
\theta_{W T}^{\alpha}(t)=\gamma_{W T}(t)+\alpha(t)
$$

It is important to note $\theta_{W T}^{\alpha}$ differs from $\theta$ due to the fact that a constant horizontal velocity is assumed in the calculation of $\gamma_{W T}$. That is not the case, if the free flying aircraft is undergoing significant pitching motion even if the flight speed does not change in magnitude significantly.

The third motion profile is derived from the insight that lift is proportional to the product of dynamic pressure and angle of attack, $q_{d} \alpha$, for small $\alpha$, as can be seen from the following expression:

$$
L=q_{d} S c_{L, \alpha} \alpha
$$

where $S$ and $c_{L, \alpha}$ represent the surface area and lift coefficient of the wing. Therefore it is proposed to adjust the pitch motion applied in the wind tunnel in such a way as to maintain the instantaneous product of $q_{d} \alpha$ in the wind tunnel the same as in the free flight. Consequently the instantaneous angle of attack in the wind tunnel must be adjusted according to:

$$
\alpha_{W T}(t)=\frac{q_{d}^{F F}(t)}{q_{d}^{W T}(t)} \alpha(t)
$$

where $q_{d}^{F F}$ and $q_{d}^{W T}$ correspond to the instantaneous dynamic pressure in free flight and in the wind tunnel, respectively. The updated profile of the pitching motion, $\theta_{W T}^{q_{d} \alpha}$, in the wind tunnel is then determined as:

$$
\theta_{W T}^{q_{d} \alpha}(t)=\gamma_{W T}(t)+\alpha_{W T}(t)
$$

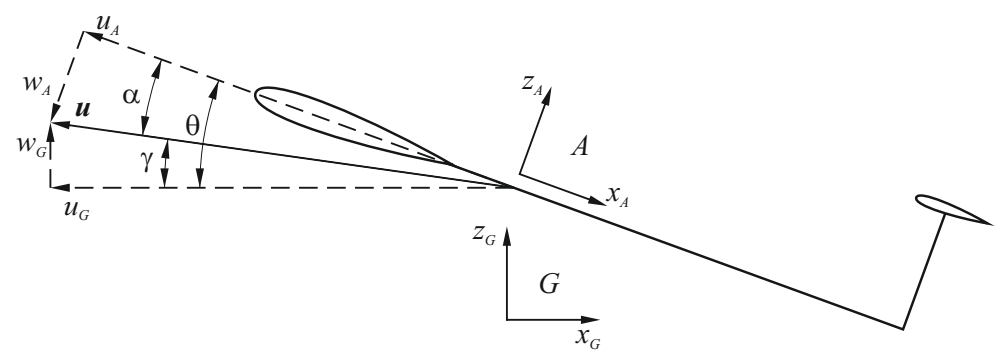

Figure 3. Relationship between aircraft flight velocity, pitch attitude and angle of attack

\section{Results}

The obtained results are discussed in this section. First, the gust response of the aircraft is briefly presented, followed by the verification of the reduced aeroelastic model comprising the main wing only. Next, the effect of mimicking free flight in the heave and pitch DOF is examined. Finally, the proposed modified motion profiles introduced at the end of Sec. III are investigated.

Figure 4 shows the gust response of the HALE aircraft in free flight for three different gust lengths. The aircraft response is presented in terms of instantaneous aircraft heave velocity, $w_{G}$, pitch angle, $\theta$, and angle 
of attack, $\alpha$, since they affect the exerted aerodynamic loads. The selected gust lengths are chosen to span a wide range of reduced frequencies, $k$, from $k=0.05$ at $l_{G}=60 \mathrm{~m}$ up to $k=0.3$ at $l_{G}=10 \mathrm{~m}$. One can observe that with increasing gust length, more of the flight dynamic response is excited as reflected by increasing perturbations in $w_{G}$ and $\theta$ after the aircraft has passed the gust. These perturbations tend to persist for a longer time, in excess of five gust lengths. On the other hand, for the short gusts, e.g. $l_{G}=$ $10 \mathrm{~m}$, the perturbations in $w_{G}$ and $\theta$ disappear shortly after the gust encounter and the aircraft settles back to the trimmed state within one to two gust lengths.

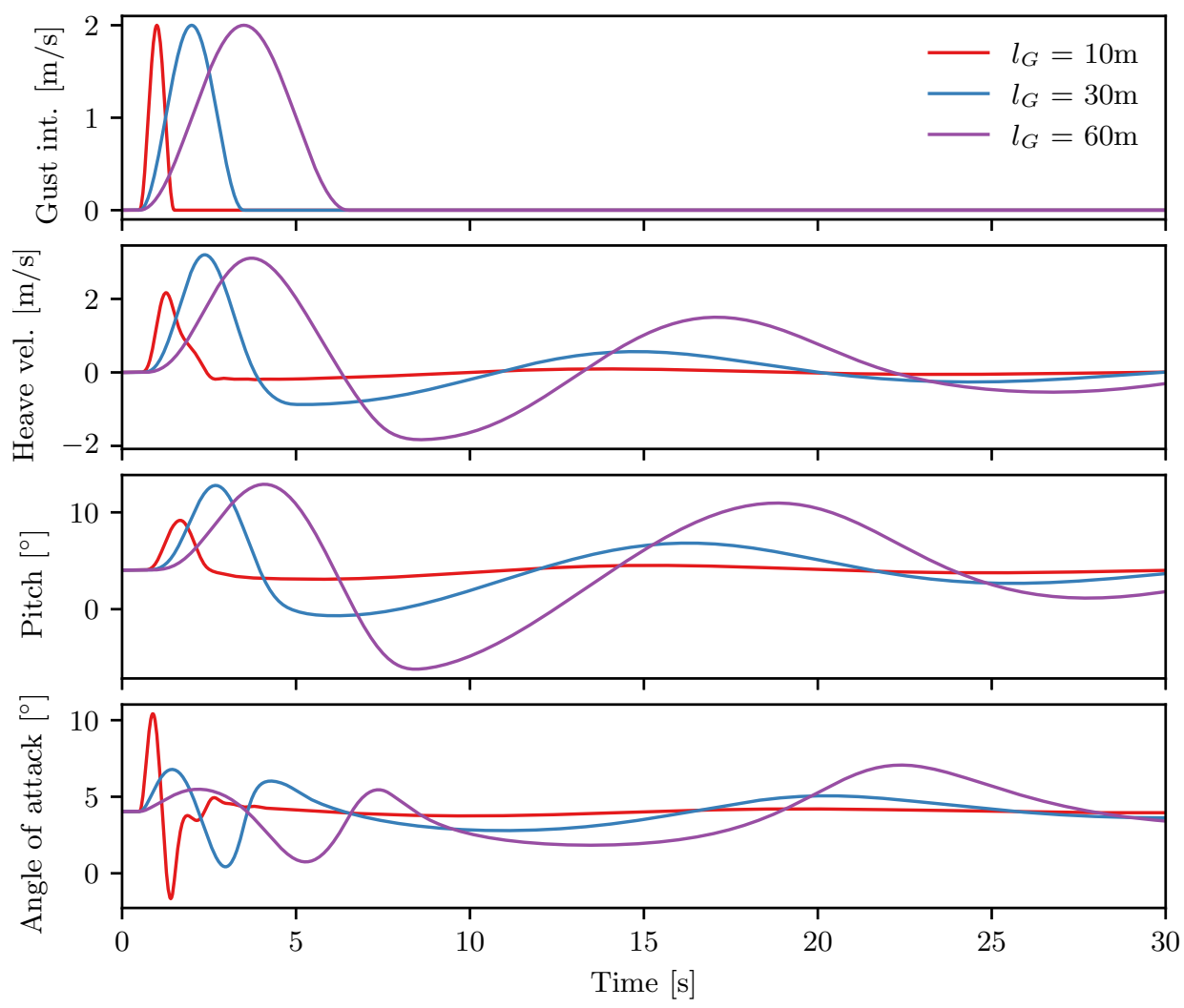

Figure 4. Relationship between the gust profile and the aircraft heave velocity, $w_{G}$, pitch attitude, $\theta$, and angle of attack, $\alpha$

Before considering the effect of various motion profiles on the aeroelastic response of the main wing, it is important to verify that the reduced aeroelastic model comprising only the main wing can account correctly for the prescribed motion at the root of the wing thereby simulating free flight. Therefore a complete motion of the wing root in terms of linear and angular velocity and acceleration vectors was extracted from the free flight simulation and re-played as a prescribed motion in SHARPy. The aeroelastic wing tip out-of-plane deflection and root bending moment in free flight and prescribed motion simulation are compared in Fig. 5. The compared aeroelastic responses match very well with a maximum difference of $0.7 \%$ and $0.9 \%$ in the wing tip deflection and root bending moment, respectively.

Following the verification of the prescribed motion simulations, the effect of mimicking the free flight motion in individual DOFs can be analysed. Again the aeroelastic response in terms of wing tip out-of-plane deflection and root bending moment is considered at several gust lengths. The main difference with respect to the preceding verification study is that only motion with pertinent velocities and accelerations along heave and pitch DOF is imposed. The motion in longitudinal direction is discarded as it is assumed that the free-stream velocity in the wind tunnel can not be changed with sufficient rate. Two scenarios, clamped, and heave-pitch, as explained in Sec. III, are compared to the free flight response. The results for gust lengths of $l_{G}=10 \mathrm{~m}, 30 \mathrm{~m}$, and $60 \mathrm{~m}$ are shown in Fig. 6 .

Clamping the wing at the root leads to a significant overestimation of both peak wing tip deflections and peak root bending moments which are indicated in Fig. 6 by circular markers. The difference increases with increasing gust length from $15 \%$ and $27 \%$ at $l_{G}=10 \mathrm{~m}$ up to $64 \%$ and $103 \%$ at $l_{G}=60 \mathrm{~m}$ for wing tip 


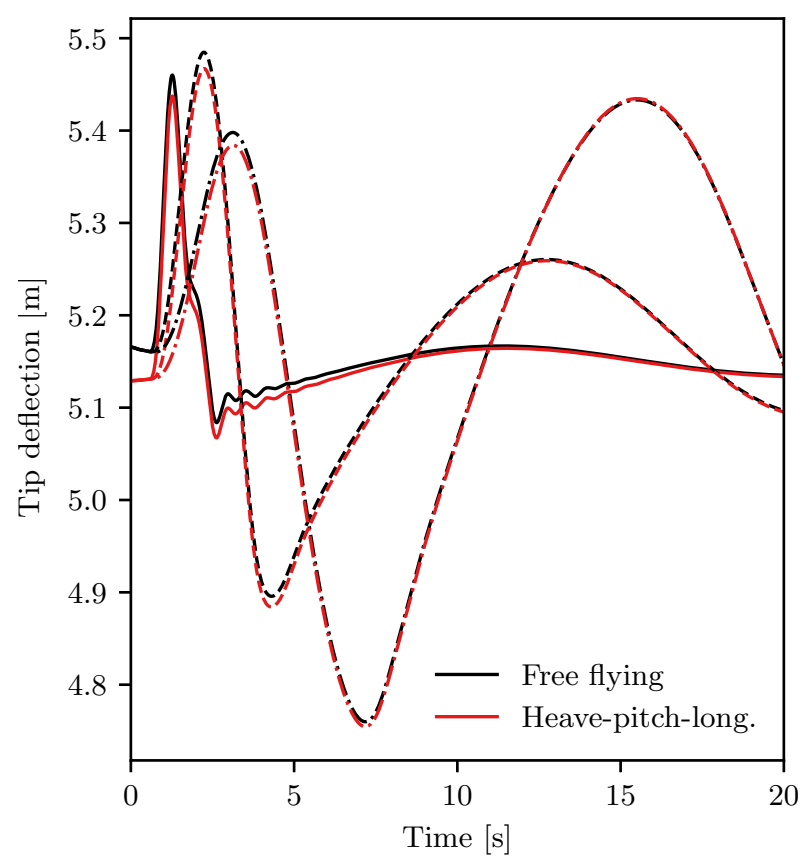

(a) Wing tip out-of-plane deflection

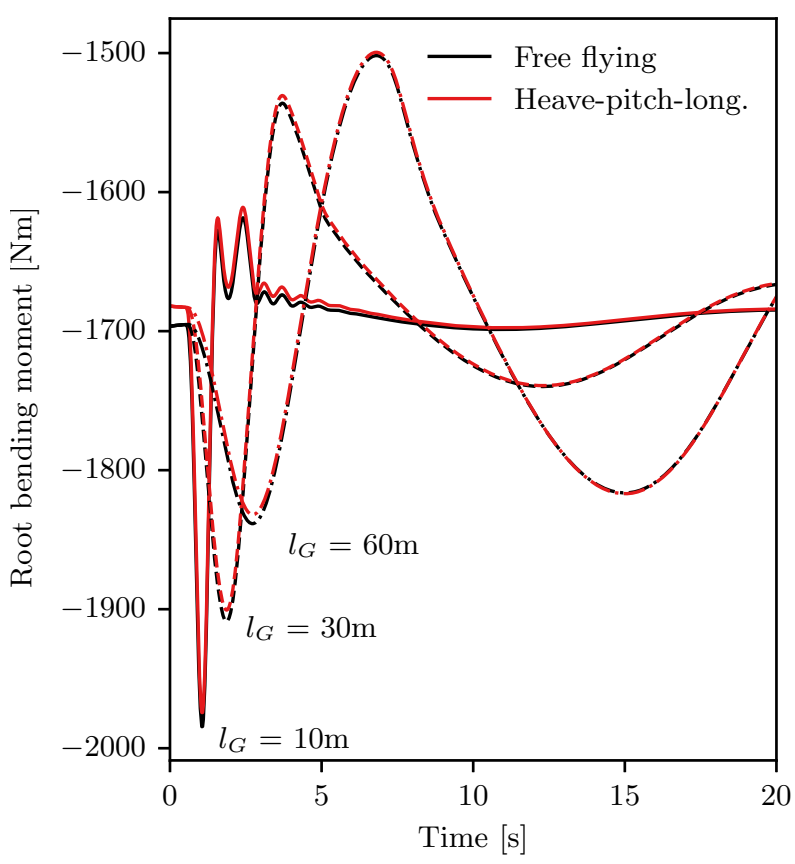

(b) Root bending moment

Figure 5. Verification of the reduced aeroelastic model comprising the main wing only in prescribed motion simulation

deflection and root bending moment, respectively. The observed differences in the aeroelastic response can be explained by the fact that the aircraft motion alleviates the aerodynamic loads which in turn reduces the magnitude of the aeroelastic response. As can be seen in Fig. 4, the flight dynamic response in the heave and pitch DOFs becomes more significant as the gust length increases, which explains why the difference between clamped and free flight aeroelastic response also increases with increasing gust length.

The peak tip deflection and bending moment pertinent to the heave-pitch results match with the freeflight results much better than the clamped results, which clearly indicates that mimicking the aircraft motion in the wind tunnel experiment can improve the fidelity of the measured aeroelastic response. Nevertheless, a similar trend with respect to gust length can be observed. As the gust length is increased, the agreement between the heave-pitch and the free flight response becomes worse. That is especially the case for the transient part of the response after the gust has already passed where the imposed heave-pitch motion considerably aggravates the response by amplifying the oscillations in both tip deflection and root bending moment. Such behaviour can be explained by analysing the imposed motion profiles and the resulting effective angle of attack including the gust-induced angle of attack as shown in Fig. 7.

The comparison of heave velocity, $w_{G}$, and pitch angle, $\theta$, between the free flight and heave-pitch shows an excellent agreement as expected. However, in the heave-pitch case, the horizontal velocity is maintained constant, $u_{G}=u_{0}$, which effectively reduces the velocity inclination angle, $\gamma$, which in combination with the imposed $\theta$ leads to an increased angle of attack in the wake of the gust as shown in the bottom plot of Fig. 7. This effect becomes more pronounced for longer gusts since these gusts affect the flight dynamic response of the aircraft more than the short gusts in this case.

To overcome the shortcomings of the clamped boundary condition and the imposed heave-pitch motion, alternative motion profiles, as proposed in Sec. III, are tested. First, a motion following the effective angle of attack of the aircraft is proposed in an attempt to simplify the experiment. Second, two modified heave-pitch motion profiles are proposed to overcome the differences originating from keeping the horizontal velocity, $u_{G}$, constant in the wind tunnel. The first heave-pitch motion profile maintains the effective angle of attack, while the second one maintains the instantaneous product of dynamic pressure and angle of attack, $q_{d} \alpha$, the same as in free flight. For the sake of conciseness, these three modified motion profiles are referred to as $A o A, H P(\alpha)$, and $H P\left(q_{d} \alpha\right)$, respectively. Their influence on the effective angle of attack is presented in Fig. 8. A number of interesting remarks can be made about these results. 


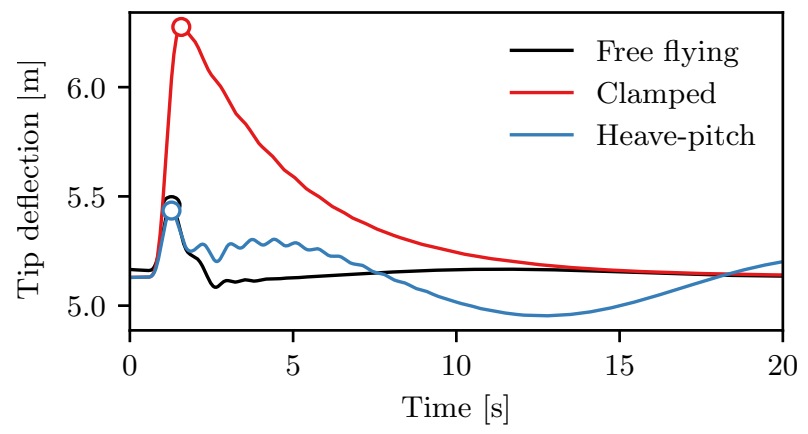

(a) Wing tip out-of-plane deflection, $l_{G}=10 \mathrm{~m}$

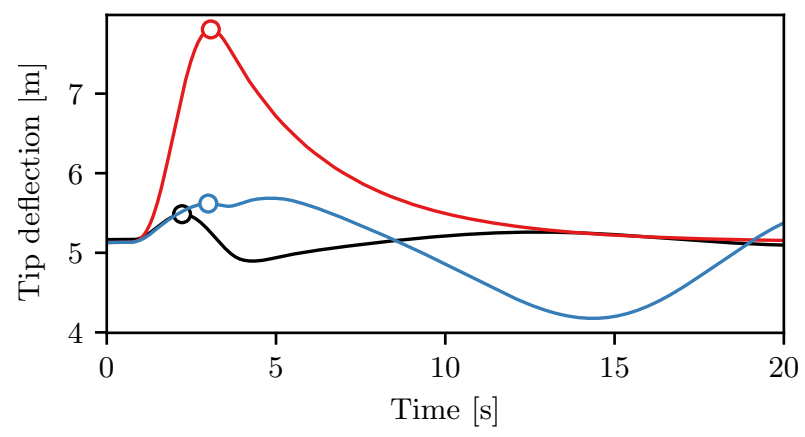

(c) Wing tip out-of-plane deflection, $l_{G}=30 \mathrm{~m}$

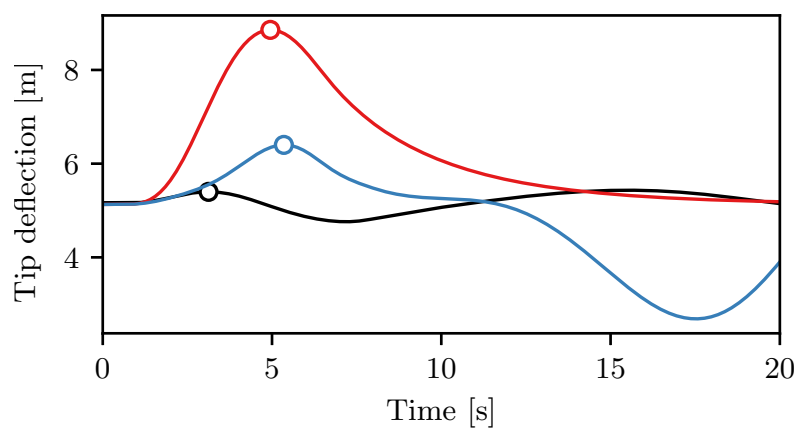

(e) Wing tip out-of-plane deflection, $l_{G}=60 \mathrm{~m}$

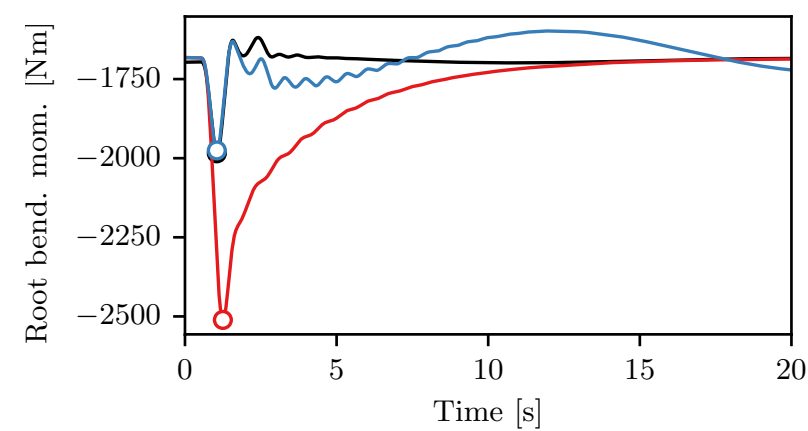

(b) Root bending moment, $l_{G}=10 \mathrm{~m}$

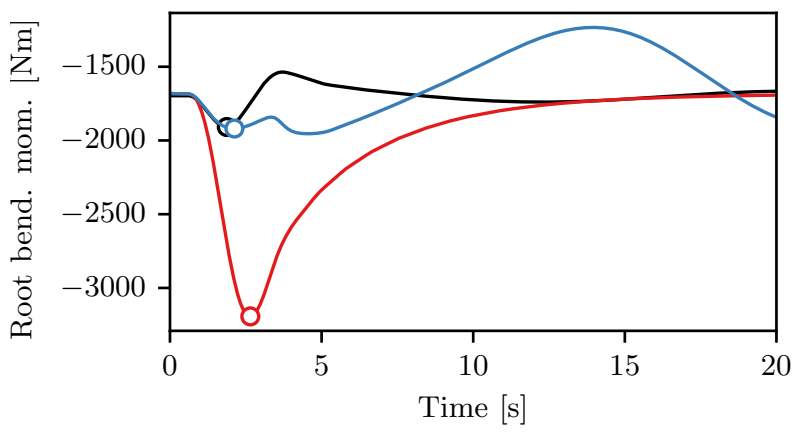

(d) Root bending moment, $l_{G}=30 \mathrm{~m}$

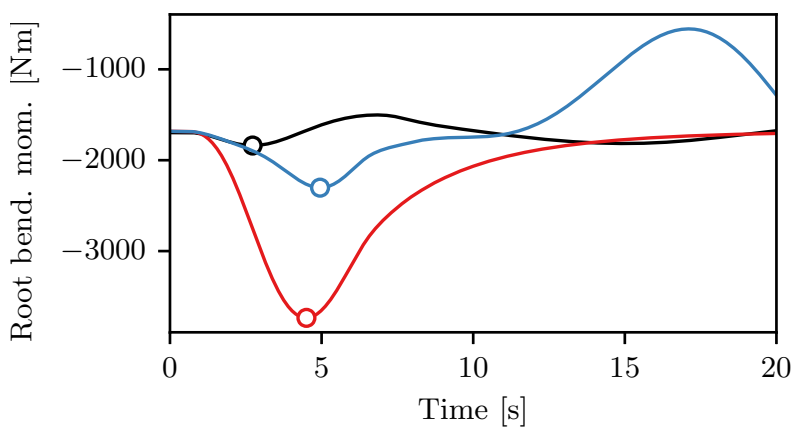

(f) Root bending moment, $l_{G}=60 \mathrm{~m}$

Figure 6. Aeroelastic response for prescribed motion in individual DOFs and gust excitation 

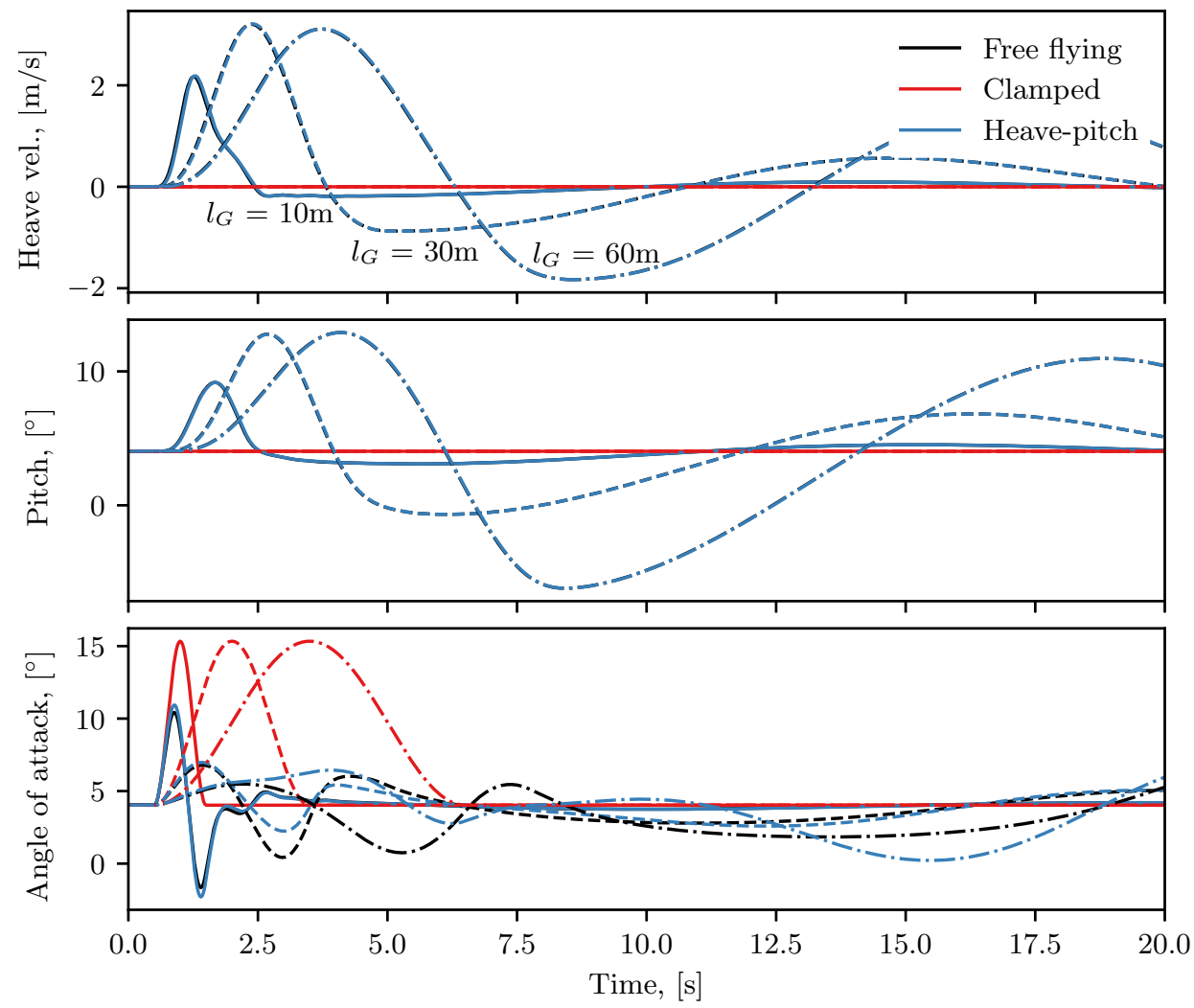

Figure 7. Relationship between the aircraft free flight and imposed heave velocity, $w_{G}$, pitch attitude, $\theta$, and angle of attack, $\alpha$, for clamped and heave-pitch motion 
First, concerning the heave DOF, the $A o A$ does not impose any motion along this DOF, while both $H P(\alpha)$, and $H P\left(q_{d} \alpha\right)$ follow the free flying motion without any modifications. Second, concerning the pitch DOF, the $A o A$ motion in this DOF corresponds to the angle of attack due to aircraft's attitude and flight dynamic motion only. Consequently it follows an entirely different pitch profile than the free flying case. However, in superposition with the gust-induced angle of attack, the resulting total angle of attack overlaps with that of the free-flying aircraft very well as can be seen in the bottom plot of Fig. 8. For $H P(\alpha)$ and $H P\left(q_{d} \alpha\right)$, the pitch motion closely follows the free flight pitch angle for shorter gusts while the differences in the pitch profiles start to increase as the gust length is increased. In the case of $H P(\alpha)$, the modified pitch profile in combination with the gust-induced angle of attack expectedly recovers the total angle of attack seen in the free flying case. Finally, the total angle of attack pertinent to the $H P\left(q_{d} \alpha\right)$ differs from the free flying case in an attempt to recover the $q_{d} \alpha$ product instead of $\alpha$. Again, the differences become more pronounced for longer gust lengths.

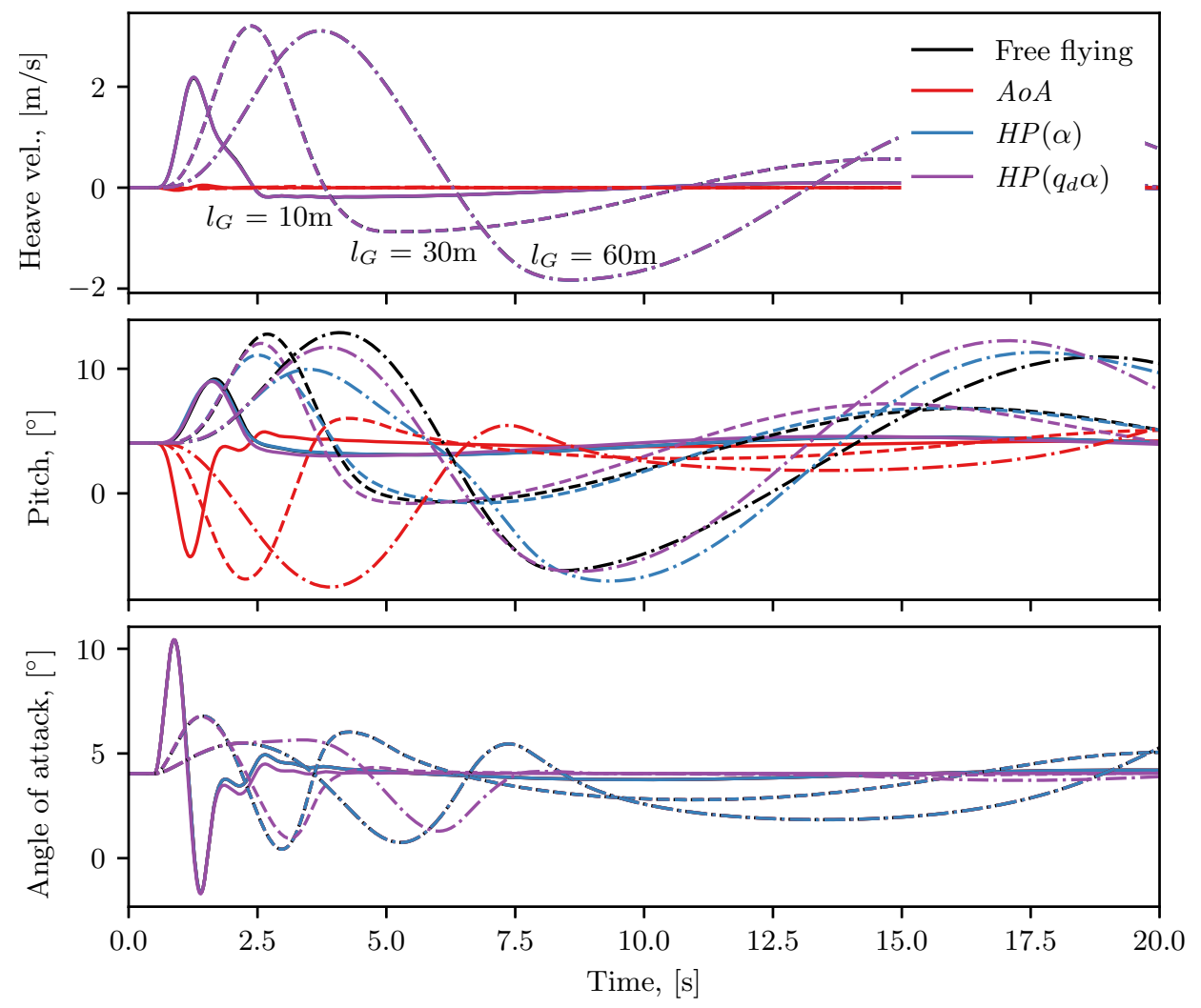

Figure 8. Relationship between the aircraft free flight and imposed heave velocity, $w_{G}$, pitch attitude, $\theta$, and angle of attack, $\alpha$, for $A o A, H P(\alpha)$, and $H P\left(q_{d} \alpha\right)$ motion

The resulting aeroelastic responses for gust lengths $l_{G}=10 \mathrm{~m}, 30 \mathrm{~m}$, and $60 \mathrm{~m}$ are presented in Fig. 9 . In general, the results of the modified motion profiles compare better to the free flying response than in the case of clamped boundary condition and the plain heave-pitch motion presented in Fig. 6 . The improvement is especially noticeable in the predicted peak loads and deflections for longer gust lengths as can be seen in Table 2. The selected peak loads used in the comparison are indicated by the circular markers in both Figs. 6 and 9.

So far, the results indicate that the mimicked free flying response in the wind tunnel can significantly differ from the the actual aeroelastic response in free flight. Therefore a more detailed study is performed to assess the performance of the increased-fidelity methodology and the effect of the various motion profiles on the predicted aeroelastic response as a function of gust length. Two metrics are considered. The first metrics is the peak out-of-plane wing tip deflection and the peak root bending moment, thereby reflecting the agreement in the direct forced response due the gust impingement. The second metrics is the correlation between the mimicked and the actual free flight response over a correlation window, $t_{\text {corr }}=3 l_{G} / u_{0}$, which reflects the agreement in the indirect transient response after the gust excitation is over. The results are 


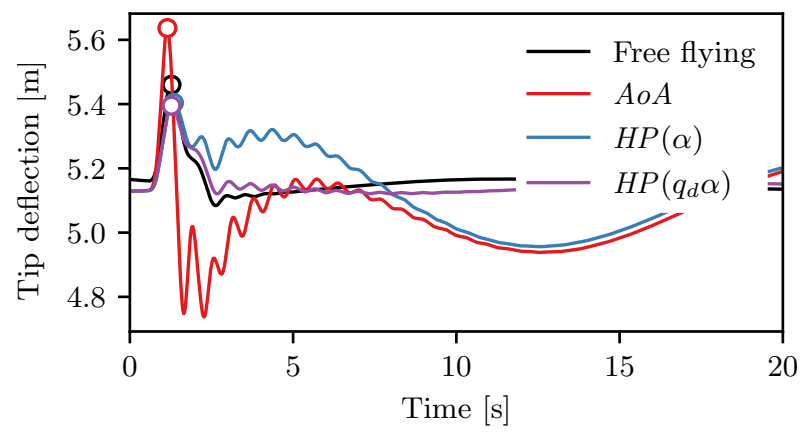

(a) Wing tip out-of-plane deflection, $l_{G}=10 \mathrm{~m}$

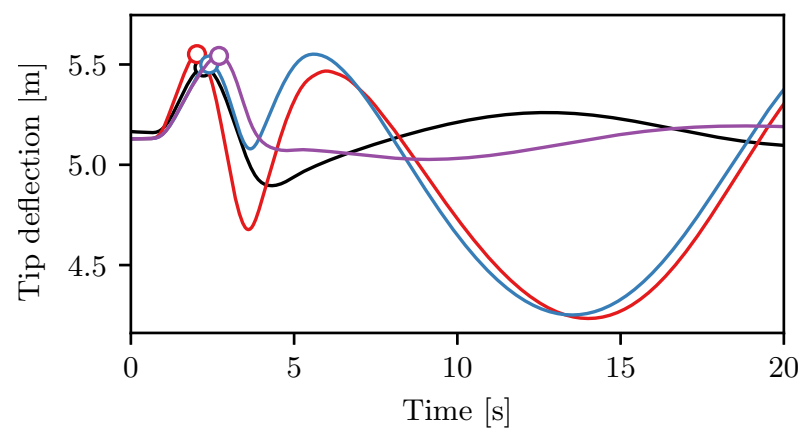

(c) Wing tip out-of-plane deflection, $l_{G}=30 \mathrm{~m}$

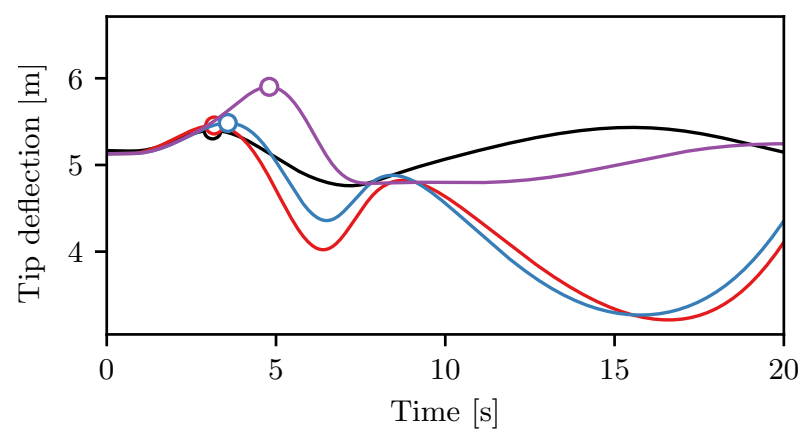

(e) Wing tip out-of-plane deflection, $l_{G}=60 \mathrm{~m}$

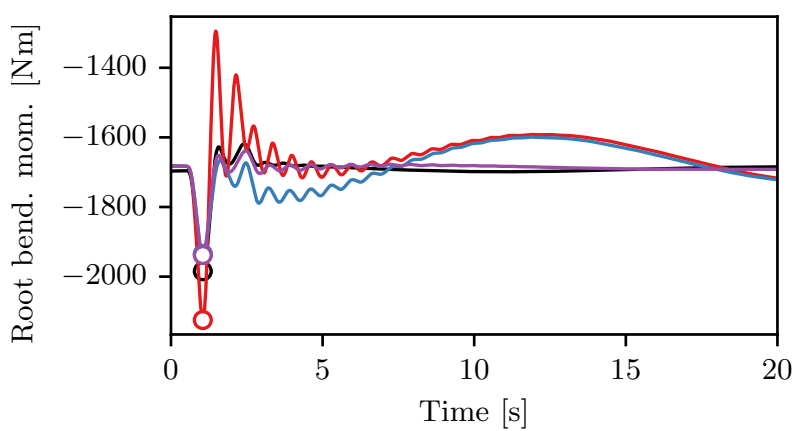

(b) Root bending moment, $l_{G}=10 \mathrm{~m}$

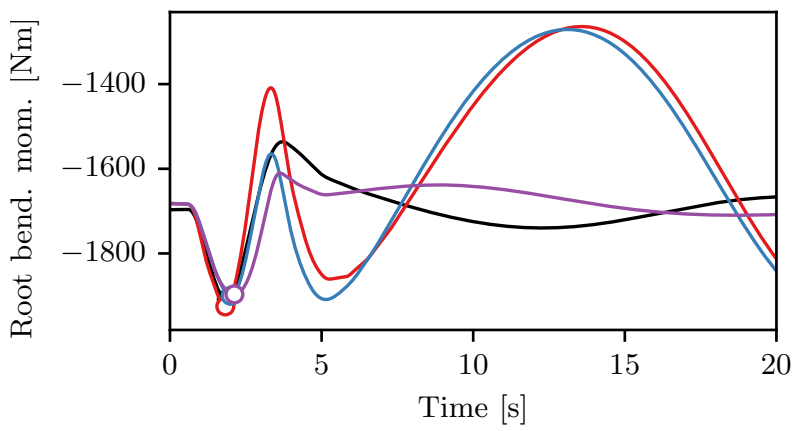

(d) Root bending moment, $l_{G}=30 \mathrm{~m}$

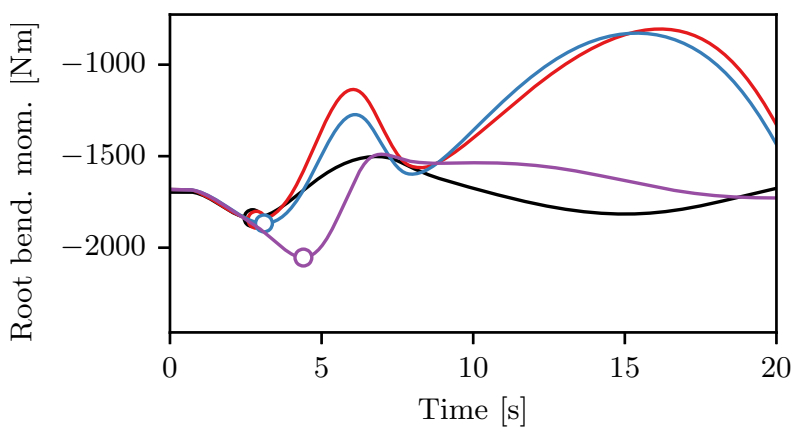

(f) Root bending moment, $l_{G}=60 \mathrm{~m}$

Figure 9. Aeroelastic response for the modified prescribed motion in individual DOFs and gust excitation

Table 2. Relative difference in peak aeroelastic response between free flight and imposed motion profiles

\begin{tabular}{rcccccccccc}
\hline & \multicolumn{4}{c}{ Wing tip out-of-plane deflection, $[\mathrm{m}]$} & \multicolumn{4}{c}{ Root bending moment, $[\mathrm{Nm}]$} \\
\hline Gust length & Clamped & $H P$ & $A o A$ & $H P(\alpha)$ & $H P\left(q_{d} \alpha\right)$ & Clamped & $H P$ & $A o A$ & $H P(\alpha)$ & $H P\left(q_{d} \alpha\right)$ \\
\hline $10 \mathrm{~m}$ & 14.9 & 0.5 & 3.2 & 1 & 1.2 & 26.5 & 0.5 & 7.1 & 2.5 & 2.3 \\
$30 \mathrm{~m}$ & 42.3 & 2.4 & 1.2 & 0.3 & 1.1 & 67.3 & 0.5 & 0.9 & 0.5 & 0.6 \\
$60 \mathrm{~m}$ & 64 & 18.6 & 1.1 & 1.6 & 9.3 & 103.1 & 25.2 & 0.5 & 1.6 & 11.7 \\
\hline
\end{tabular}


presented in Figs. 10 and 11.

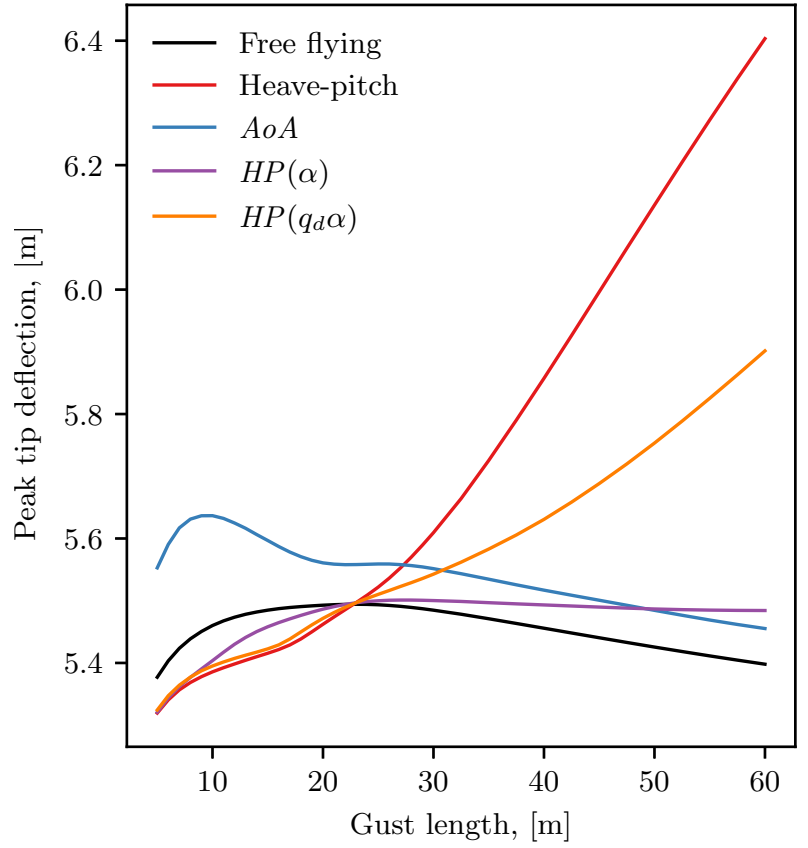

(a) Wing tip out-of-plane deflection

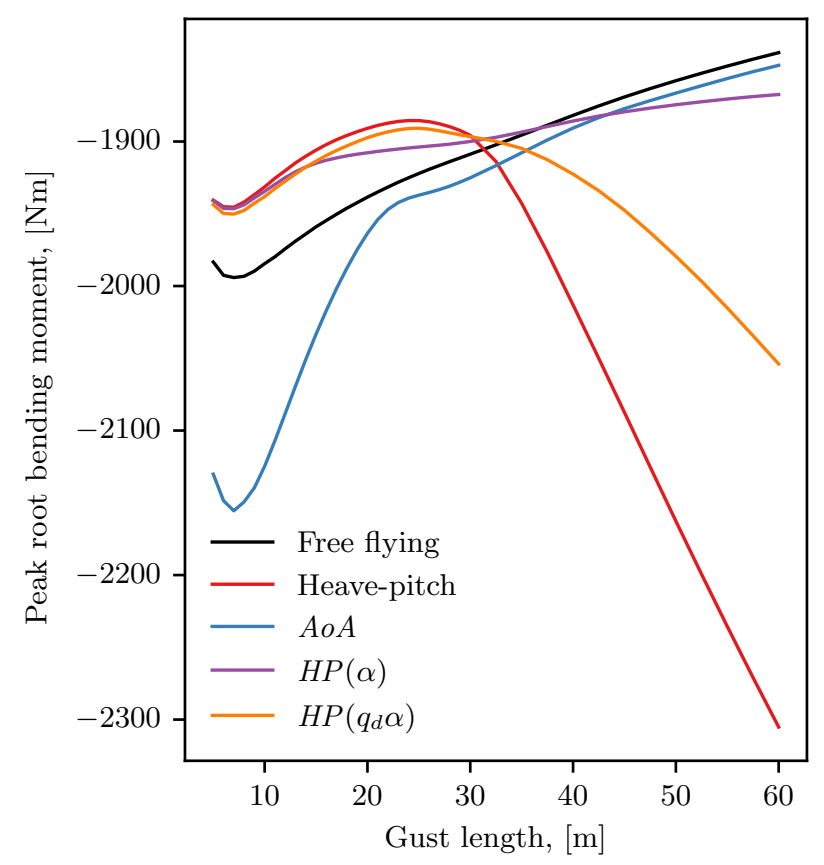

(b) Root bending moment

Figure 10. Wing aeroelastic response as a function of gust length

Fig. 10 shows, that the best motion profile to mimic the direct gust response depends on the gust length. For shorter gusts, $l_{G}<30 \mathrm{~m}$, the motion profiles including both heave and pitch, perform the best with very little difference among themselves. This indicates that for short gust response the heave motion of the aircraft has the dominant influence. For longer gusts, $l_{G}>45 \mathrm{~m}$, the $A o A$ profile performs the best, thereby indicating that in this case the effective angle of attack is dominant. Interestingly, the $H P(\alpha)$ performs the best over the widest range of gust length, $5 \mathrm{~m}<l_{G}<45 \mathrm{~m}$ among all the considered motion profiles. This is surprising, since one would expect that the $H P\left(q_{d} \alpha\right)$ would be the best motion profile since, it is expected to match the aerodynamic loads in free flight to the best degree. However, in addition to the aerodynamic loads, the inertial loads due to all the mass in the wing also affect the aeroelastic response. The effect of various motion profiles on the inertial loads could explain the differences observed between the different heave-pitch motion profiles. However, it remains to be investigated in the future.

Considering the correlation results with free flight presented in Fig. 11, the $H P\left(q_{d} \alpha\right)$ clearly out-performs all the other motion profiles by maintaining a high level of correlation, above 0.9 , for gust lengths $l_{G}<20 \mathrm{~m}$ and $25 \mathrm{~m}$ for the wing tip deflection and root bending moment, respectively. The correlation for all the other motion profiles drops below 0.9 well below $l_{G}=10 \mathrm{~m}$ for both, the wing tip deflection as well as the root bending moment. The correlation results show that the indirect transient response to gust excitation is poorly predicted by the considered motion profiles mimicking the free flight conditions in the wind tunnel. The $q_{d} \alpha$ correction significantly improves the prediction for short to moderately long gusts, $l_{G}<30 \mathrm{~m}$, however for longer gusts, $l_{G}>30 \mathrm{~m}$, the prediction is still unsatisfactory. Similarly to the direct forced response, the effect of the various motion profiles on the exerted inertial loads might have an important influence on the indirect transient response as well.

\section{Wind tunnel demonstrator design}

A demonstrator to serve as a proof-of-concept of the increased-fidelity aeroelastic testing methodology is based on the aeroelastic apparatus developed by Gjerek et al. ${ }^{21}$ and is shown in Fig. 12a. The apparatus allows for a wide range of variations in both stiffness and mass properties as can be seen in Table 3. Consequently, it is easy to configure the stiffness properties of the "flexible" wing to yield interesting aeroelastic phenomena such as large deflections, flutter or divergence onset, at the airstream velocities attainable in the 


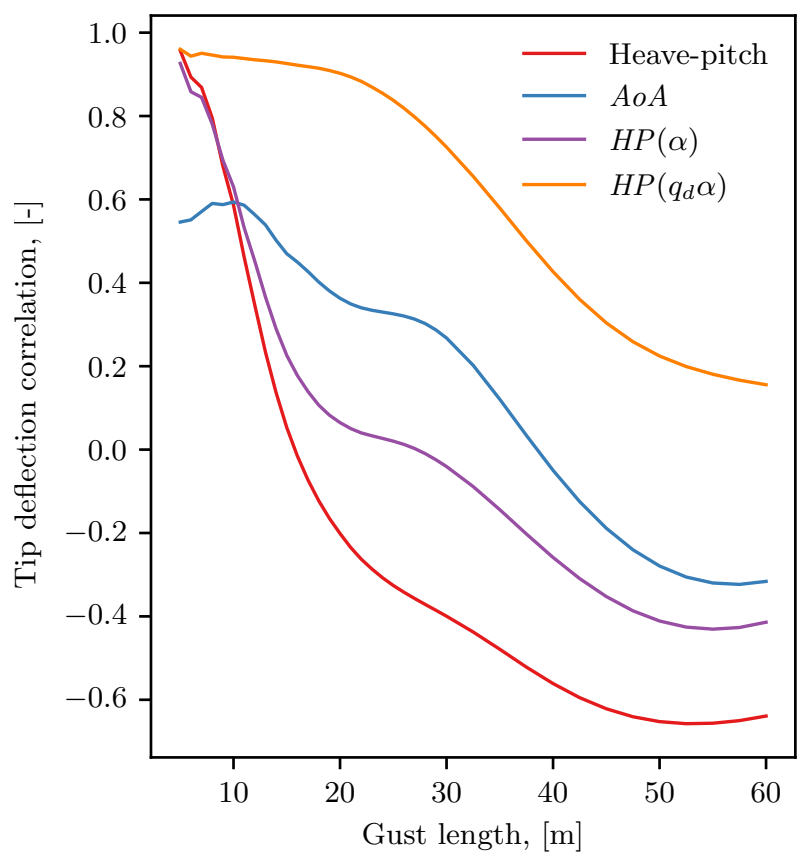

(a) Wing tip out-of-plane deflection

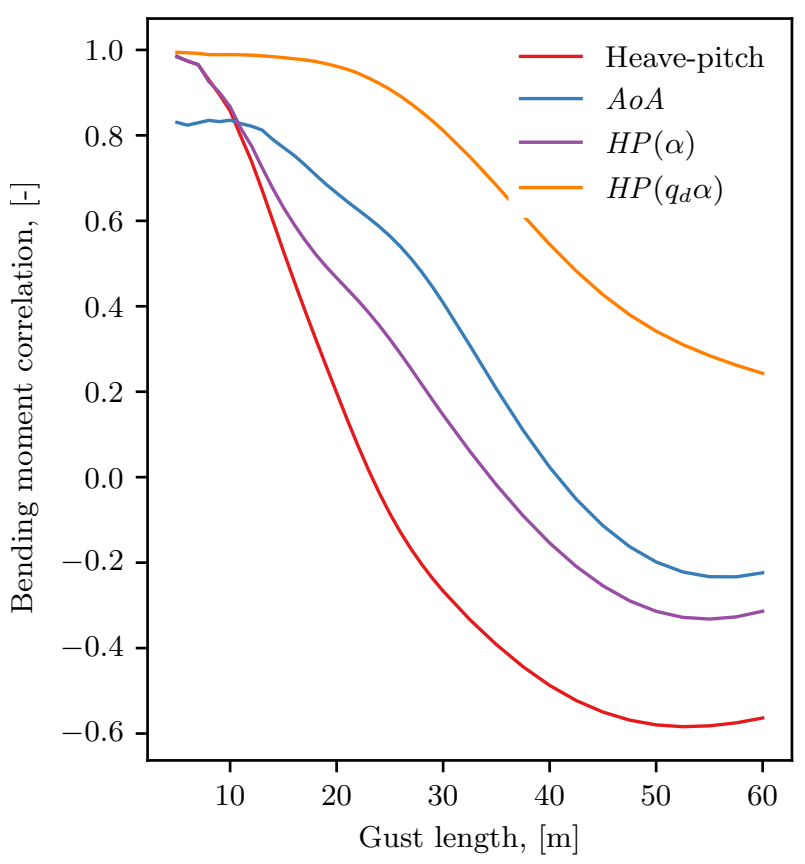

(b) Root bending moment

Figure 11. Aeroelastic response correlation with free flight as a function of gust length

wind tunnel.

To be able to demonstrate the increased-fidelity aeroelastic testing, the apparatus must be modified by the introduction of the actuated heave and pitch DOFs as shown in Fig. 12b. The actuation of the heave and pitch DOFs is realised by using a linear and rotary motion stage actuated using servomotors.

The experiment is designed to be conducted in the M-tunnel at Delft University of technology. M-tunnel is an open-circuit blow-down wind tunnel. The tunnel has a test section of $0.4 \mathrm{~m} \times 0.4 \mathrm{~m}$ and can reach airstream velocity of $v_{0}=30 \mathrm{~m} / \mathrm{s}$. The wind tunnel is equipped with a gust generator which can provide harmonic and 1-cosine gust excitation in the frequency range between $0.5 \mathrm{~Hz}$ and $12 \mathrm{~Hz} .{ }^{22}$

The motion control of the apparatus is performed using a model implemented in Simulink, ${ }^{23}$ which runs in real time on a BeagleBone Blue ${ }^{\mathrm{b}}$ (BBB) single board computer. The BBB allows for easy acquisition of analog and digital input signals from various sensors such as load and displacement transducers, as well as the generation of the pulse-width-modulated (PWM) signals required to control the servo actuators. Since the behaviour of the BBB is controlled through a Simulink model, it can be easily reconfigured to follow various motion profiles either in feedforward or feedback manner.

The simulink model is based on a simplified aircraft model shown in Fig. 13. For the sake of simplicity, all the structural flexibility and damping of the model is lumped in the pitch and heave stiffness of the wing, $k_{\theta}$ and $k_{h}$, along with their respective damping coefficients, $\zeta_{\theta}$ and $\zeta_{h}$. The rest of the model, the fuselage and the tail, is considered rigid. In addition, the model is limited in motion in the longitudinal plane to rigid body pitch and heave DOF, $\theta_{a c}$ and $h_{a c}$, and to elastic pitch and heave DOF of the main wing, $\theta_{w}$ and $h_{w}$. Geometric, mass, and inertia properties of the aircraft are governed by the centre of gravity (C.G.) relative to the nose of the aircraft, $l_{f, w, t}$, mass, $m_{f, w, t}$, and moment of inertia, $I_{f, w, t}$, of the individual components comprising the aircraft: the fuselage, the wing and the tail, respectively. The model parameters are chosen in such a manner to simplify the execution of parametric studies of various aircraft configurations.

Finally, there are two domains indicated in Fig. 13: hardware-in-the-loop (HIL) and software-in-the-loop (SIL). The two domains partition the aircraft into the hardware model, the actual components to be tested in the wind tunnel, and the numerical model used to determine the required response of the actuated platform to simulate the free-flying aircraft boundary condition.

\footnotetext{
bhttps://beagleboard.org/blue, accessed on September 25, 2021
} 


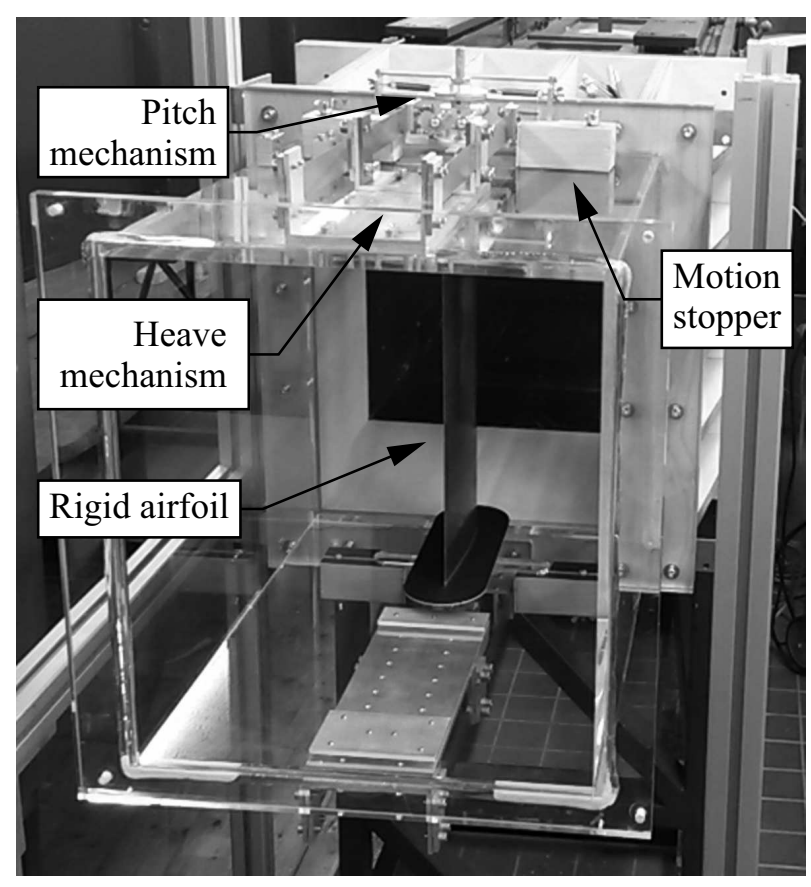

(a) Existing experimental apparatus

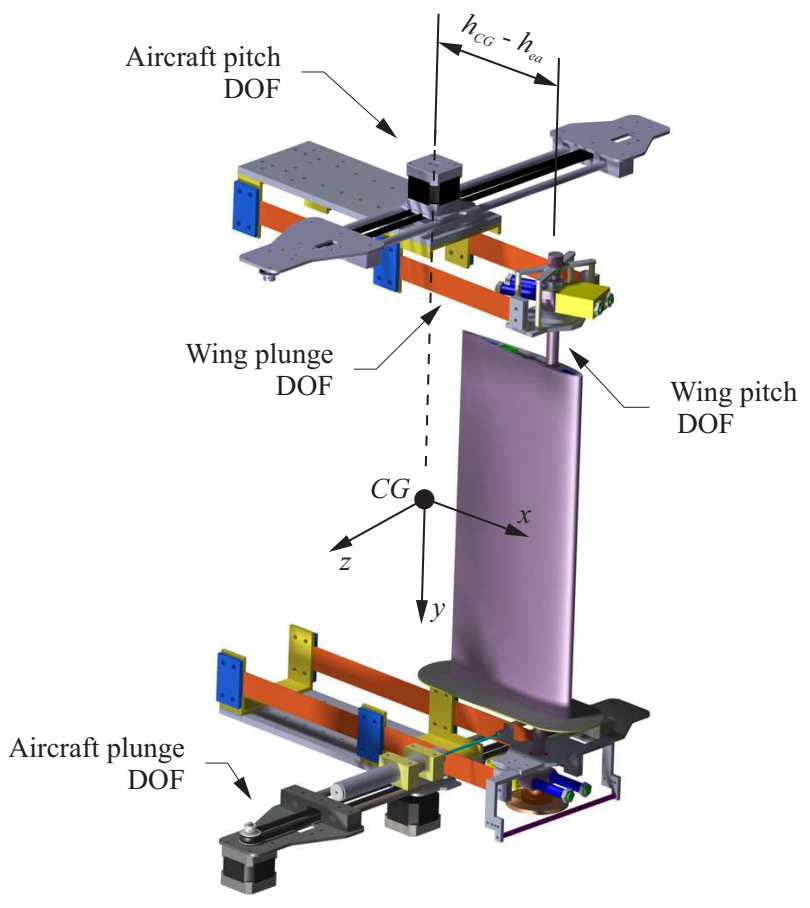

(b) Modification of the aeroelastic apparatus

Figure 12. Experimental setup

Table 3. Physical properties of the experimental setup

\begin{tabular}{rrc}
\hline \multicolumn{1}{c}{ Parameter } & Unit & Quantity \\
\hline airfoil & {$[-]$} & NACA 0012 \\
chord $\times$ span, $2 b \times s$ & {$\left[\mathrm{~m}^{2}\right]$} & $0.16 \times 0.36$ \\
airfoil mass, $m_{0}$ & {$[\mathrm{~kg}]$} & 0.622 \\
heave mass, $m^{*}$ & {$[\mathrm{~kg}]$} & 0.441 \\
moment of inertia, $J_{0}$ & {$\left[\mathrm{kgm}^{2}\right]$} & $1.92 \cdot 10^{-3}$ \\
axis of rotation, $(1+a) b$ & {$[\mathrm{~m}]$} & $0.04-0.12^{\dagger}$ \\
CG, $\left(1+e_{0}\right) b$ & {$[\mathrm{~m}]$} & 0.067 \\
heave stiffness, $k_{h}$ & {$[\mathrm{~N} / \mathrm{m}]$} & $676-2100^{\dagger}$ \\
heave damping, $D_{h}$ & {$[\mathrm{Ns} / \mathrm{m}]$} & $0.8-1.5^{\ddagger}$ \\
pitch stiffness, $k_{\theta}$ & {$[\mathrm{Nm} / \mathrm{rad}]$} & $0.52-4.24^{\dagger}$ \\
pitch damping, $D_{\theta}$ & {$[\mathrm{Nms} / \mathrm{rad}]$} & $0.0066-0.0035^{\ddagger}$ \\
\hline
\end{tabular}

$\dagger$ Range of attainable values.

$\ddagger$ Depends on the system configuration. 


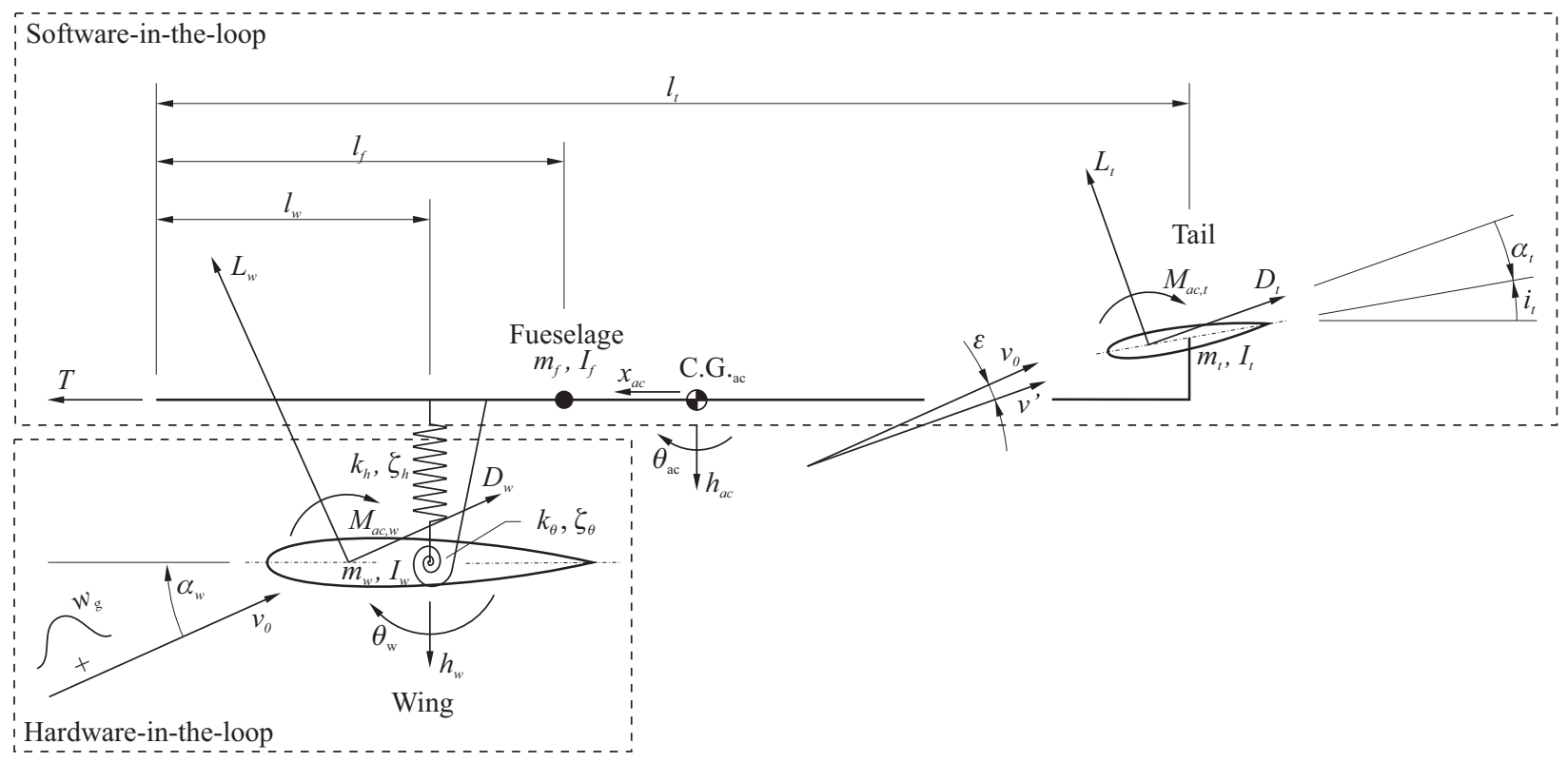

Figure 13. Aircraft model

\section{Conclusion}

A methodology for increased-fidelity aeroelastic testing is proposed in the current paper which aims to increase the fidelity of aeroelastic tests conducted in a wind tunnel by emulating the response of a free flying aircraft using an actuated motion platform. As a result, the hardware complexity of the aeroelastic model is reduced, since only a specific aircraft subcomponent of interest, such as the main wing of the aircraft, is required in a physical form. Finally, the proposed methodology simplifies the execution of parametric wind tunnel tests, since many parameters pertinent to the aircraft configuration can be modified in the numeric part of the model.

The assessment of various motion profiles used to emulate a 1-cosine gust response of a HALE aircraft in free flight indicates that the proposed increased-fidelity testing has the potential to improve the fidelity of the aeroelastic response of the main wing in a simulated wind tunnel experiment. The difference between the simulated wind tunnel test and the free flying aircraft, in terms of the peak wing tip deflection and peak root bending moment, can be reduced from more than $50 \%$ for the clamped mounting condition to less than $5 \%$ when using the considered motion profiles. The effectiveness of a specific motion profile depends on the gust length. Motion profiles based on combined heave and pitch are the best at emulating the free flight response to short and medium length gusts, while the motion profile based on angle of attack is the best for long gusts.

When considering the transient part of the aeroelastic response, after the gust has passed the wing, the correlation between the increased-fidelity and free flight aeroelastic response decreases significantly with increasing gust length. Correlation drops rapidly below 0.90 beyond the gust length of $25 \mathrm{~m}$ for all the considered motion profiles. The exact cause of such large differences at longer gust lengths remains to be determined in the future investigations. In this context, it is also clear, that an optimum motion profile that is able to capture both direct forced and the indirect transient aeroelastic response must be optimised in future investigations.

A wind tunnel demonstrator is proposed to apply the increased-fidelity aeroelastic testing in the wind tunnel and to proof the concept in practice. The conceptual design of the demonstrator is complete, however, the detailed design and the realisation remain future work.

\section{References}

${ }^{1}$ Tang, D. and Dowell, E. H., "Experimental and theoretical study of gust response for high-aspect-ratio wing," AIAA Journal, Vol. 40, No. 3, 2002, pp. 419-429. 
${ }^{2}$ Mai, H., Neumann, J., and Hennings, H., "Gust response: a validation experiment and preliminary numerical simulations," 15th International Forum on Aeroelasticity and Structural Dynamics, 2011, pp. 1-20.

${ }^{3}$ Liu, Y., Xie, C., Yang, C., and Cheng, J., "Gust response analysis and wind tunnel test for a high-aspect ratio wing," Chinese Journal of Aeronautics, Vol. 29, No. 1, 2016, pp. 91-103.

${ }^{4}$ Bi, Y., Xie, C., An, C., and Yang, C., "Gust load alleviation wind tunnel tests of a large-aspect-ratio flexible wing with piezoelectric control," Chinese Journal of Aeronautics, Vol. 30, No. 1, 2017, pp. 292-309.

${ }^{5}$ Lancelot, P., Sodja, J., and De Breuker, R., "Investigation of the Unsteady Flow Over a Wing Under Gust Excitation," International Forum on Aeroelasticity and Structural Dynamics, IFASD 2017, 2017.

${ }^{6}$ Handojo, V., Meddaikar, Y. M., and Dillinger, J. K. S., "Investigation of Gust Loads on a Flexible, Aeroelastically Tailored Forward Swept Wing," International Forum on Aeroelasticity and Structural Dynamics, No. June, 2019, pp. 2-4.

${ }^{7}$ Sodja, J., Werter, N., Dillinger, J. K., and De Breuker, R., "Dynamic Response of Aeroelastically Tailored Composite Wing: Analysis and Experiment," 57th AIAA/ASCE/AHS/ASC Structures, Structural Dynamics, and Materials Conference, American Institute of Aeronautics and Astronautics, Reston, Virginia, jan 2016.

${ }^{8}$ Govers, Y., Mai, H., Arnold, J., Dillinger, J. K. S., Pereira, A. K. A., Jr, C. B., Takara, E. K., Correa, M. S., Mello, O. A. F., Marques, R. F. A., Geurts, E. G. M., and Creemers, R. J. C., "Wind Tunnel Flutter Testing on a Highly Flexible Wing for Aeroelastic Validation in the Transonic Regime Within the HMAE1 Project," IFASD 2019: 18th International Forum on Aeroelasticity and Structural Dynamics, No. June, 2019, pp. 1-25.

${ }^{9}$ Silva, W., Perry, B., Florance, J., Sanetrik, M., Wieseman, C., Stevens, W., Funk, C., Hur, J., Christhilf, D., and Coulson, D., "An Overview of the Semi-Span Super-Sonic Transport (S4T) Wind-Tunnel Model Program," 53rd AIAA/ASME/ASCE/AHS/ASC Structures, Structural Dynamics and Materials Conference $<$ BR $>20$ th AIAA/ASME/AHS Adaptive Structures Conference $<B R>14$ th AIAA, No. April, American Institute of Aeronautics and Astronautics, Reston, Virigina, apr 2012, pp. 1-18.

${ }^{10}$ Florance, J., Scott, R., Keller, D., Sanetrik, M., Silva, W., and Perry, B., "Lessons in the Design and Characterization Testing of the Semi-Span Super-Sonic Transport (S4T) Wind-Tunnel Model," 53rd AIAA/ASME/ASCE/AHS/ASC Structures, Structural Dynamics and Materials Conference $<$ BR $>20$ th AIAA/ASME/AHS Adaptive Structures Conference $<$ BR $>14$ th $A I A A$, No. April, American Institute of Aeronautics and Astronautics, Reston, Virigina, apr 2012, pp. 1-20.

${ }^{11}$ Tang, D., Grasch, A., and Dowell, E. H., "Gust Response for Flexibly Suspended High-Aspect Ratio Wings," AIAA Journal, Vol. 48, No. 10, oct 2010, pp. 2430-2444.

12 Jordan, P. F. and Smith, F., "A Wind-Tunnel Technique for Flutter Investigations on Swept Wings with Body Freedoms," Tech. Rep. 2893, Aeronautical Research Council, London, 1955.

${ }^{13}$ Gaukroger, D. R., Chapple, E. W., and Milln, A., "Wind-Tunnel Flutter Tests on a Model Delta Wing under Fixed and Free Root Conditions," Tech. Rep. A.R.C. Technical Report, Aeronautical Research Council, London, 1955.

${ }^{14}$ Ricci, S., Fonte, F., De Gaspari, A., Riccobene, L., Mantegazza, P., Toffol, F., and Livne, E., "Development of a Wind Tunnel Model for Active Flutter Suppression Studies," AIAA Scitech 2019 Forum, No. January, American Institute of Aeronautics and Astronautics, Reston, Virginia, jan 2019, pp. 1-14.

${ }^{15}$ Fonte, F., Ricci, S., and Mantegazza, P., "Wind tunnel evaluation of a static output feedback controller for gust load alleviation on a regional aircraft," 17th International Forum on Aeroelasticity and Structural Dynamics, IFASD 2017, Vol. 2017June, No. June, 2017, pp. 1-14.

${ }^{16}$ Ertveldt, J., Schoukens, J., Pintelon, R., and Vanlanduit, S., "Experiments on the active aeroelastic test bench (AATB) for the identification of unsteady aerodynamics," International Forum on Aeroelasticity and Structural Dynamics, IFASD 2015, 2015, pp. 1-20.

17 Tang, D., Chen, L., Tian, Z. F., and Hu, E., "Developing a virtual stiffness-damping system for airfoil aeroelasticity testing," Proceedings of the IEEE International Conference on Industrial Technology, Vol. 2019-Febru, No. 1, 2019, pp. 96101.

${ }^{18}$ Del Carre, A. and Palacios, R., "Efficient Time-Domain Simulations in Nonlinear Aeroelasticity," AIAA Scitech 2019

Forum, American Institute of Aeronautics and Astronautics, Reston, Virginia, jan 2019.

$\checkmark{ }^{19}$ del Carre, A., Muñoz-Simón, A., Goizueta, N., and Palacios, R., "SHARPy: A dynamic aeroelastic simulation toolbox for very flexible aircraft and wind turbines," Journal of Open Source Software, Vol. 4, No. 44, dec 2019, pp. 1885.

${ }^{20}$ Stengel, R., Flight Dynamics, Princeton University Press, 2004.

${ }^{21}$ Gjerek, B., Drazumeric, R., and Kosel, F., "A Novel Experimental Setup for Multiparameter Aeroelastic Wind Tunnel Tests," Experimental Techniques, Vol. 38, No. 6, nov 2014, pp. 30-43.

${ }^{22}$ Geertsen, J. A., Development of a Gust Generator for a Low Speed Wind Tunnel, Msc thesis, ETH Zurich, 2020.

${ }^{23}$ MathWorks, "Simulink - Simulation and Model-Based Design," 2020. 